Gregory, P. H. \& Hirst, J. M. (1957). J. gen. Microbiol. 17, 185-152

\title{
The Summer Air-Spora at Rothamsted in 1952
}

\author{
BY P. H. GREGORY \\ Imperial College of Science and Technology, London, S.W. 7 \\ AND J. M. HIRST \\ Rothamsted Experimental Station, Harpenden, Hertfordshire
}

\begin{abstract}
SUMMARY: The air over an arable field at Rothamsted Experimental Station, Harpenden, was sampled from 1 June to 25 October 1952 at $2 \mathrm{~m}$. above ground with an automatic volumetric spore trap. Each day's slide was scanned and all the spores counted on an area representing a sample volume of $41 \mathrm{l}$. of air. Spores were classified in 20 morphological groups and a miscellaneous one. Seasonal periodicities are presented as 6-day running means of the daily average number of spores $/ \mathrm{m}^{8}{ }^{8}$ air, and then related to meteorological data. Cladosporium conidia accounted for $46 \%$ of the total catch; hyaline basidiospores (chiefly Sporobolomyces) for $31 \%$; and pollen only $1 \%$. The relative frequency of various spore types differs from that recorded by earlier workers because the suction trap catches spores of all sizes with almost equal efficiency and is little influenced by external conditions. The results which should be representative of large rural areas of central and south England show that the major changes of spore concentration depend on the weather and the phenology of the local vegetation and its associated fungal flora. During 24 days in late June and July comparable estimates of spore concentration were made with another trap $24 \mathrm{~m}$. above ground. The spore concentration of the twelve commonest groups at $24 \mathrm{~m}$. totalled $82 \%$ of that at $2 \mathrm{~m}$.
\end{abstract}

The sampling of air continuously over long periods for air-borne microorganisms was first practised by Schoenauer (1876) and by Miquel (1877-99) at the Observatoire Municipal Montsouris, Paris. Some of their methods collected representative samples but others were selective. Selective methods have been used in most subsequent surveys, either intentionally (Neill \& Armstrong, 1955) or because the traps used caught spores with variable efficiency (Gregory, 1950) and favoured the recognition of certain groups. Long-period surveys have usually relied on exposing sticky microscope slides or Petri dishes (Bernstein \& Feinberg, 1942; Walton \& Dudley, 1940).

Both slides and Petri dishes catch large spores more efficiently than small ones and the efficiency of both depends on wind speed; also dishes are exposed only for short periods and record only those organisms that grow to form macroscopic colonies. The data we present are derived from the catches by automatic volumetric spore traps, which are much less affected by changes in wind speed and which catch spores of greatly differing size with almost equal efficiency (Hirst, 1952). The catches, examined microscopically under an oilimmersion objective, are therefore thought to reveal the relative and absolute frequency of all air-borne spores larger than $3 \mu$. more accurately than was possible until now. The method is limited by the difficulty of classifying spores visually; more specialized methods will be required for further study of many groups. 


\section{METHODS}

\section{Trapping methods}

Two traps were used; one ( $\operatorname{trap} A$ ) with its orifice $2 \mathrm{~m}$. above ground level, from 1 June to 25 October 1952, and the other (trap B) at a height of $24 \mathrm{~m}$. above ground level from 20 June to 13 July 1952.

Trap A was that originally described by Hirst (1952). It was placed on the Garden Plots Enclosure, Great Field III, Rothamsted Experimental Farm, Harpenden (National Grid Reference TL 132133), just over $400 \mathrm{ft}$. above sea level, $c$. $\frac{1}{2}$ mile south and west of the built-up area of Harpenden (population 17,000 ) and 25 miles N.N.E. of the centre of London. The nearest open sea is about 50 miles to the east and 70 miles to the south, but the prevailing southwesterly wind has a fetch, over land, of some 120 miles after crossing the Dorset coast. The crops and vegetation of the district are fairly typical of rural conditions in the south of England. The vegetation of the area within a quarter of a mile radius of the trap is shown in Fig. 1. The trap was placed at the centre of an almost square $\frac{1}{4}$ acre plot of maincrop potatoes, primarily to study the dispersal of the sporangia of the potato blight fungus Phytophthora infestans. This crop and the field of barley to the south-west which became heavily infected with powdery mildew (Erysiphe graminis) supplied more spores of these types than was typical of the district.

Trap B was similar in all essential features, except that an oil seal was incorporated in the column which allowed completely free rotation of the wind vane and impactor assembly, without interfering with continuous suction. This modification makes the apparatus more compact, allows the orifice to be placed as little as $\frac{1}{2} \mathrm{~m}$. above ground level, and made it easier to fix it to a bracket on the outside of a lattice mast $24 \mathrm{~m}$. above ground level. When so fixed the trap was $22 \mathrm{~m}$. above trap A and $100 \mathrm{~m}$. to the S.S.E. It was in use continuously from 20 June to 13 July 1952, except for 29 June.

\section{Weather and phenology in the summer of 1952}

Daily records of sunshine, rainfall, temperature and humidity, obtained from instruments adjacent to trap $\mathbf{A}$ or in the meteorological enclosure close to trap B, are presented in Fig. 2, as 6-day running means.

Conditions in spring allowed cereal crops to be drilled early but snow late in March delayed the planting of root crops. Plants grew rapidly during April and May, both warm months with sunshine and rainfall near average. Grasses came into flower during late-May and June and an average hay crop was harvested between 6 and 30 June. June and July were unusually warm and dry. Despite lack of rain, cereal crops continued to grow well; they ripened earlier than usual and harvest began on 23 July. Temperatures remained slightly above average in August, when there was nearly twice as much rain as the average, which interfered with the cereal harvest and favoured the growth of saprophytic moulds. Root crops, which had suffered from the midsummer drought, grew rapidly both in August, and in September which was a cold wet month. Potato plants, already maturing in August, were attacked by potato 
blight during the second half of the month and during September. The autumn flush of toadstools (Agaricaceae) began, as usual, in August but was checked by a dry spell at the end of the month. The usual peak in September was not reached, perhaps because low temperatures and damaging frosts occurred unusually early.

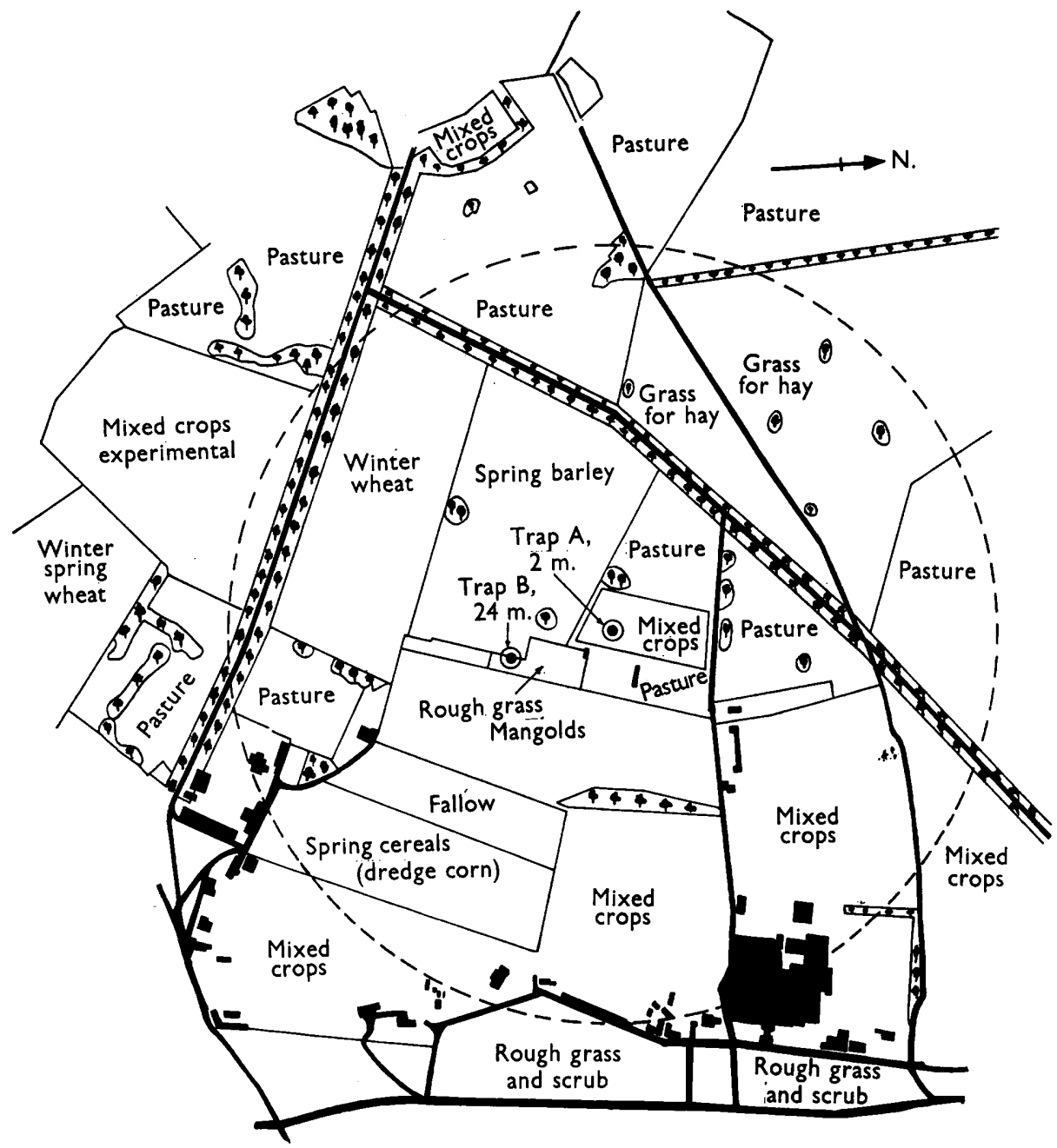

Fig. 1. Map showing position of traps and vegetation in 1952 . Dotted circle is a quarter mile radius from trap $\mathbf{A}$.

\section{Scanning procedure}

The slides, prepared as described by Hirst (1953, p. 377), were changed daily at $09.00 \mathrm{hr}$. G.M.T., and all estimates of daily mean spore concentration apply to the $24 \mathrm{hr}$. preceding $09.00 \mathrm{hr}$. on the date quoted. As most of the data are presented as 6-day running means, the discrepancy from the daily period midnight to midnight is immaterial. 
Daily mean concentrations of various types of spores were estimated from counts of spores on a single narrow traverse parallel to the direction in which the slide moved while in the trap ('long traverses', see Hirst, 1953, p. 378).

This method of scanning is relatively rapid and samples the whole of the exposure period, but it does not reveal the typical diurnal periodicities of the spore types or the brief maximum concentrations, which a cursory glance showed were many times greater than the daily mean. Each traverse was $40 \mu$. wide and approximately $50 \times 1000 \mu$. long, or $2 \mathrm{~mm}^{2}$ in area; pollens and uredospores were counted on traverses twice this width. A traverse $40 \mu$. wide corresponds to a sample air volume of $41 \cdot 15 \mathrm{l}$./day. A sample of this size allows accurate estimation of only the more abundant forms. This type of trap concentrates many spores on a small area, so that little time is wasted in scanning empty areas. For instance there were on average over 120 Cladosporium conidia $/ \mathrm{mm}^{2}$ of slide surface throughout the whole period, and on the peak day the number rose to $770 / \mathrm{mm}^{2}$. A larger area could have been scanned in the same time had an objective of lower magnification been used, but experience shows that it is desirable to use an oil-immersion objective with a magnification of $\times 45$ and a focal length of $3.75 \mathrm{~mm}$., otherwise minute hyaline spores, such as those of Sporobolomyces and Tilletiopsis, may be missed altogether.

The counts were not corrected for variations in the efficiency of trapping, (Hirst, 1953, p. 378) which was assumed to be $100 \%$. The actual efficiency depends on the wind speed and the size of particle and averages about $80 \%$. Thus all the spore numbers quoted are underestimates of the true concentration. Counts represent the total number of spores; those joined together in clumps as one dispersable unit were counted as separate individuals. This convention makes it easier to estimate the weight of any spore type in a sample of air, but is less suitable for estimating the number of reproductive units deposited/unit area.

Classification of the spores caught could be based only on microscopic evidence. We have therefore had to use special categories, which are varyingly related to standard taxonomic categories. Inorganic particles and fragments of plants unlikely to be viable were ignored. The spore categories used are arranged, for convenience of presentation, in the order shown in Fig. 2, which is divided arbitrarily into scales based on the approximate frequency of the spores at their seasonal maximum. The categories were originally chosen after a preliminary examination of all the slides, to give the most useful and reliable grouping possible by spore morphology alone. The homogeneity of the categories varies greatly. A few are probably limited to individual species, but others are very wide and ill-defined. The categories are in general 'form groups' and were devised after comparison with many reference slides of carefully identified spores and pollens. Each category is discussed individually in the next section. 


\section{THE COMPOSITION OF THE AIR-SPORA TWO METRES ABOVE GROUND}

The salient features of the seasonal changes in the composition of the airspora $2 \mathrm{~m}$. above ground are shown in Fig. 2, where the categories are divided into 4 groups each plotted on a different scale. On scale $\mathbf{A}$ a unit represents 20 spores $/ \mathrm{m}^{3}{ }^{3}$ air; on scale $B-D$ it represents 100,500 and 5000 spores $/ \mathrm{m}^{3}$, respectively. This not only aids graphical presentation, but also stresses the importance of the two groups in scale $D$.

Table 1. Contributions of categories of spores to the whole air-spora (see text)

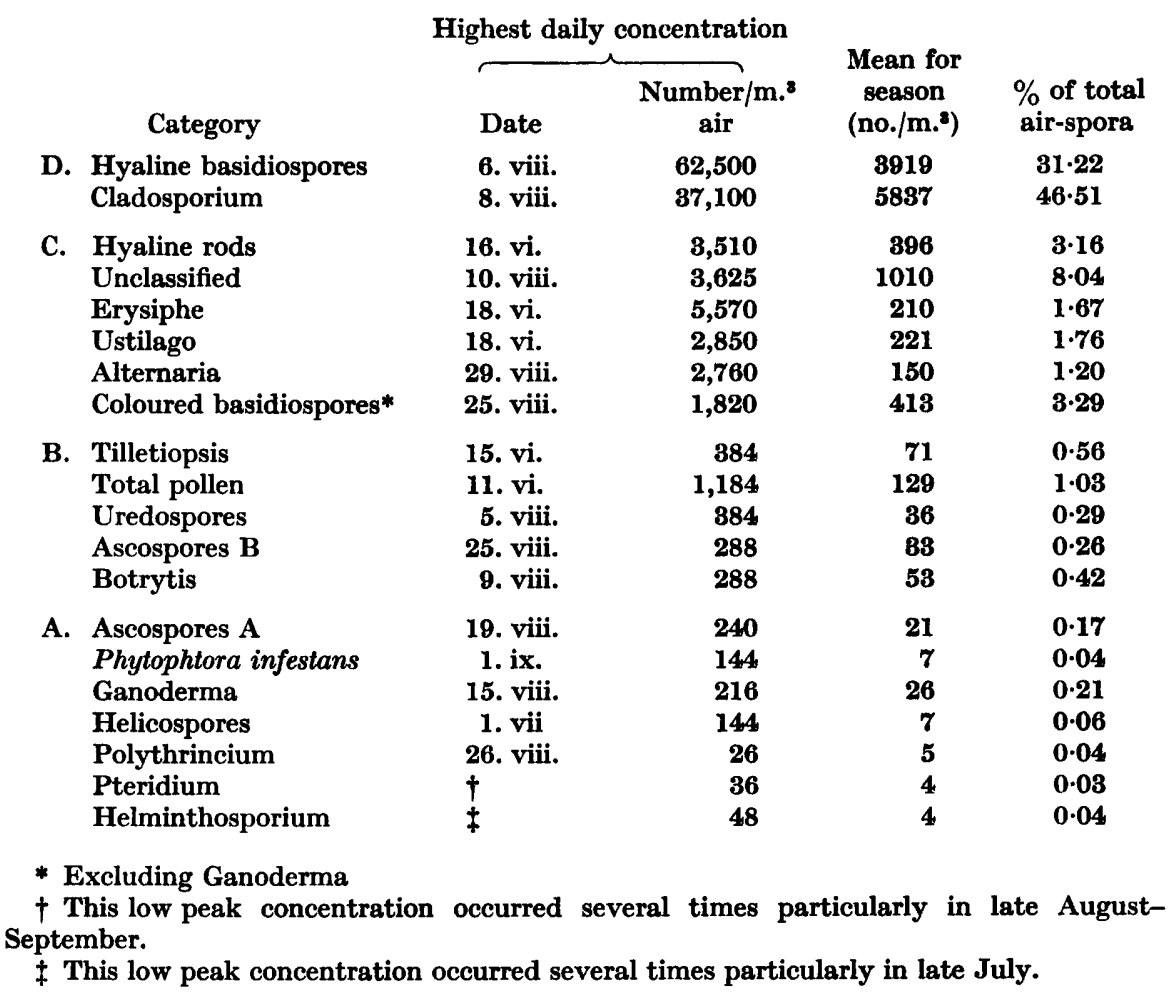

The changing frequency of each category is shown by a 6-day running mean curve of the estimated average number of spores $/ \mathrm{m} .{ }^{3}$ air throughout each day. To decrease the amount of calculation and tabulation required, these values were plotted only at 3-day intervals, which smooths out short-term weather changes and makes it easier to study the effects of long spells of weather and phenological changes. Day-to-day changes in spore concentration are similarly obscured, so the highest of the daily average concentrations for each category are shown in Table 1, together with the average over the whole 150-day period ( 1 June to 25 October) and the percentage which each contributed to the total of the whole air-spora. 


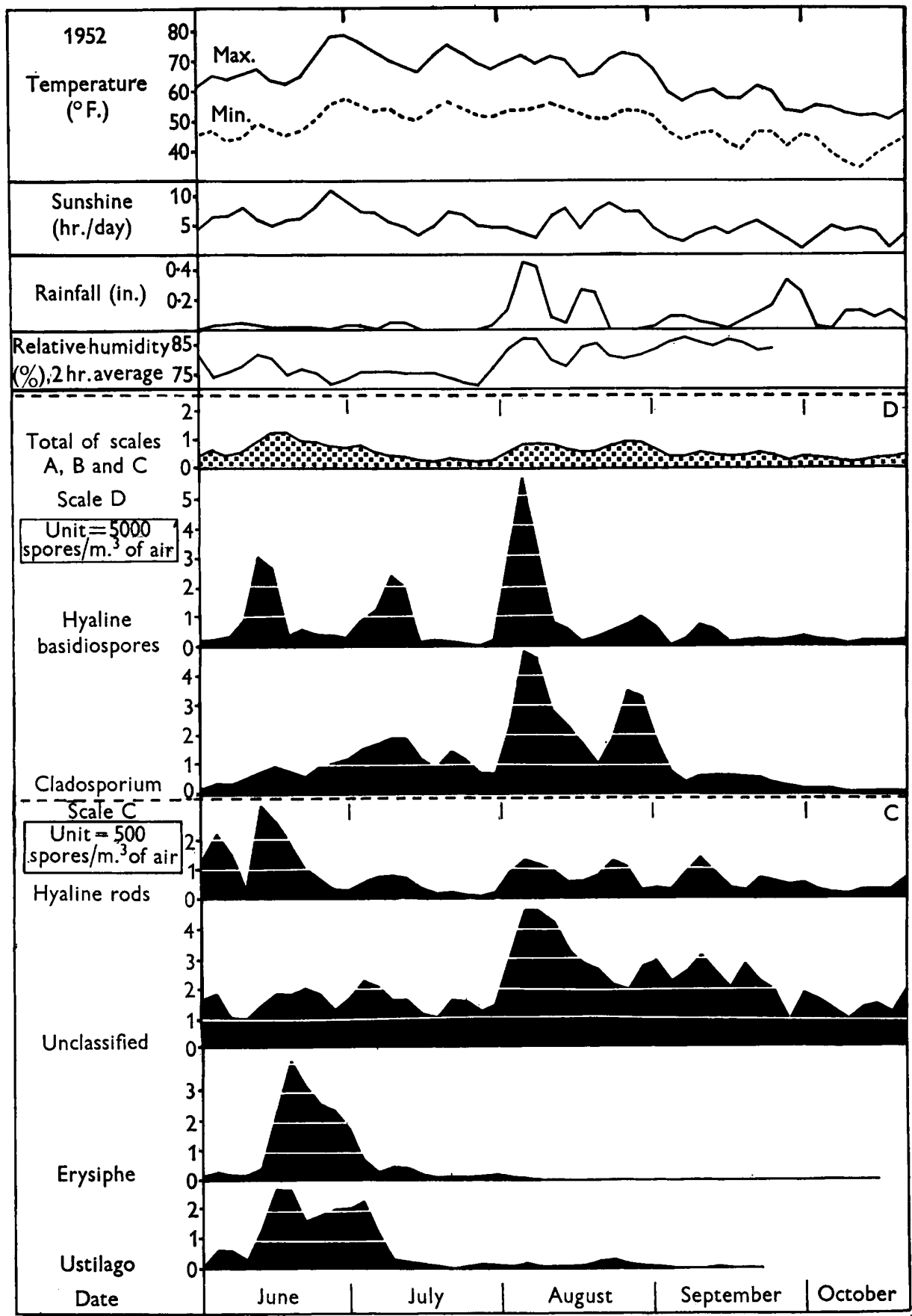

Fig. 2. Weather and seasonal periodicity of spore concentration $2 \mathrm{~m}$. above ground, 1 June to 25 October, 1952. Curves are 6-day running means plotted at 3-day intervals. 


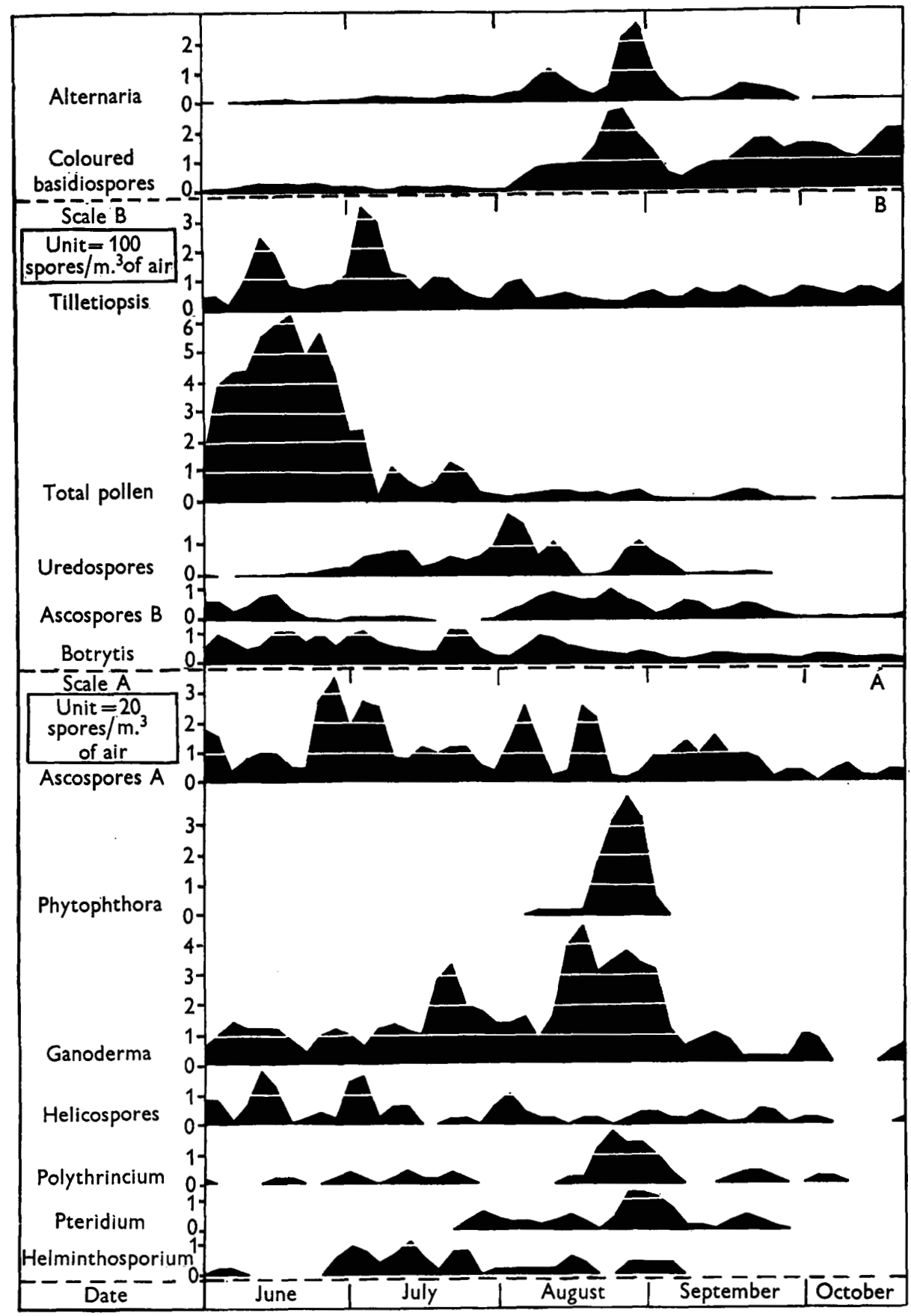

Fig. 2 (continued) 


\section{Helminthosporium type (Fig. 2, scale A)}

Typified by the cylindrical, multi-septate, thick-walled conidia of Helminthosporium avenae, this distinctive group probably includes very few spores not belonging to this genus. The group featured prominently in surveys by earlier workers, but it does not in ours. Partly this is because our method of trapping is not biased in favour of catching large and heavy spores, though the difference may be partly due to the modern methods of controlling diseases of cereal crops by fungicidal seed dressings. Wild grasses or pastures probably formed the main source, but the highest concentration observed was of the same order as the $34 / \mathrm{m} .^{3}$ recorded by Grainger (1954) above an oat crop infected with $\boldsymbol{H}$. avenae during the peak period of spore liberation. The group was commonest in dry warm weather.

\section{Pteridium type (Fig. 2, scale A)}

Typified by the spores of Pteridium aquilinum, the bracken fern, which are large and have a characteristic shape, colour and ornamentation, this is probably another homogeneous group. There are no large areas of bracken within several miles of the trap site but small quantities occur within one mile. These spores were caught most frequently in warm dry weather from late July to September. The sporangia of $\boldsymbol{P}$. aquilinum, like those of many other ferns, depend on desiccation for dehiscence and spore ejection (Ingold, 1939).

\section{Polythrincium trifolii type (Fig. 2, scale A)}

This group of very characteristic spores was founded on specimens of the Polythrincium conidial state of Cymadothea (Dothidella) trifolii, the cause of clover blotch. All spores included probably belonged to this species, which was common on wild white clover (Trifolium repens) all around the trap sites. The group, separated because of its biological interest, occurred throughout the period, but never in large numbers. Hirst (1953) found that it had a diurnal periodicity suggesting that drying liberated the spores. Wet weather decreased the number in the air, but most were caught in late August after a wet period and coincident with the peak of Phytophthora infestans.

\section{Helicosporium type (Fig. 2, scale A)}

This group includes any hyaline conidia coiled in a flat spiral. They probably come from cereals and grasses, for spores of this type, belonging to an unidentified species of Helicosporium, have often been found on dead culms of wheat at Rothamsted. The group was present throughout the season and occurred during rain, which suggests that dispersal may be aided by rain splash, although this is difficult to reconcile with the similarity of Helicosporium's seasonal periodicity to that of Tilletiopsis. Most occurred during warm spells in June and July and, in common with many other groups, few spores were caught in the cold spell in October. 


\section{Ganoderma type (Fig. 2, scale A)}

This group was based on reference slides of the basidiospores of Ganoderma applanatum (Polyporaceae) of which there are several sources in the neighbourhood. The spores are characteristic, with an outer hyaline wall penetrated by projections of the inner brown wall. They probably all belong to G. applanatum since the less common $G$. lucidium has smaller spores. This group was present continuously except during the cold spell in October. It was most common in August and during the dry spell in July.

\section{Phytophthora infestans type (Fig. 2, scale A)}

This fungus, causing late blight of potato, is another of the types which can be referred to a species with reasonable certainty. The only other downy mildews present in recognizable quantity, Peronospora effusa and $P$. parasitica were placed in the Unclassified group. $P$. infestans sporangia can be distinguished from these by their size, shape, colour and the character of the papilla and stalk. The potato crop in which the trap was placed was an abundant source and the numbers recorded are therefore atypical of the district as a whole.

\section{Ascospores type A (filiform type, see Hirst, 1953; Fig. 2, scale A)}

Most of the obvious ascospores were placed in the 'Unclassified' group, for want of features that allowed definite identification, but two very characteristic although arbitrary form groups were recorded separately. Type A consisted of long filiform spores resembling reference slides of ascospores of Epichloe typhina, but no doubt including spores from diverse genera such as Claviceps, Geoglossum, Cordyceps, etc. Some filiform conidia of Fungi Imperfecti may have been included, but they probably form only an insignificant part of the group. Ascospores type A occurred typically in damp air during rain but they were also to be found with high humidity at night. Dews probably caused some liberation and may explain the considerable numbers caught during the dry spell in July. (The second group, Ascospores type B, is described below, after Botrytis).

\section{Botrytis type (Fig. 2, scale B)}

Spores of this type resemble those of Botrytis cinerea and form a characteristic group defined by their shape, faint colour, and the way in which they shrivelled slightly in the mountant we used. There were numerous local sources of this nearly ubiquitous fungus, on withered petals and moribund plants, as well as sources of specialized species that cause diseases of vegetables and ornamentals. They were present throughout the season, but were most common in the earlier part. Day-to-day changes were small, but the spores were more common in the air in the daytime than at night. 
Ascospores type B (Fusiform type, see Hirst, 1953; Fig. 2, scale B)

The other distinctive type of ascospore separated was of fusiform multiseptate spores, with one of the intermediate cells distinctly swollen. These spores were probably derived from saprophytic pyrenomycetes such as Leptosphaeria. They also are characteristic of damp air but their seasonal periodicity differed considerably from that of the filiform spores included in type A, perhaps because their spores need wetter conditions for liberation. Their concentration increased with humidity, particularly when other factors indicate that the air close to the ground remained wet. They did not show the July peak which is a feature of group $\mathbf{A}$.

\section{Uredospore type (Fig. 2, scale B)}

This category included all spores which could be recognized unquestionably as uredospores of rust fungi (Uredineae). Uredospores of less common species may have been placed in the Unclassified group. Wheat, barley and grasses no doubt formed the main source. Crops of wheat within a few hundreds yards of the trap were infected with $P$ uccinia glumarum, $P$.triticina and $P$.graminis and a nearby barley crop with $\boldsymbol{P}$. anomala. Rust diseases of cereals were more than usually common in 1952, uredospores were nevertheless only a minor component of the air-spora. Most uredospores were caught in warm spells, particularly in August, and the numbers declined rapidly after mid-September, presumably because of harvesting.

\section{Total pollens (Fig. 2, scale B)}

Three pollen categories were used: 'winged' (mostly Pinus), 'grass' and 'others'. The last was mainly weeds, including Chenopodiaceae and Urtica. Sampling was started after the season of pollen liberation by deciduous trees, so few of these are included in the miscellaneous group. As the incidence of pollens has been studied elsewhere (Hyde, 1952) only the concentration of total pollens is given in Fig. 2. The grass pollen group was predominant, particularly during the peak period in June. The seasonal periodicity of the total pollen group is governed chiefly by the flowering of grasses, and release, which is favoured by warm sunny weather, is greatest in the daytime (Hyde \& Williams, 1945, 1946; Hirst 1953).

\section{Tilletiopsis type (Fig. 2, scale B)}

This type consists of minute basidiospores often folded hinge-like into unequal parts. The group is so distinctive that it was counted separately before it was shown that the spores were identical with the basidiospores (ballistospores) of Tilletiopsis. Last (1955a) showed that this genus, a member of the Sporobolomycetaceae and close relative of the pink 'mirror yeasts', is a common epiphytic fungus on the leaves of cereals in summer. It is interesting 
to note that it was most common in June and July concurrently with peak numbers of 'Helicospores', during spells with warm nights and moderately high average relative humidity.

\section{Coloured basidiospore type (Fig. 2, scale C)}

The basidiospores produced by many fungi belonging to the Agariacaceae and related families are characterized by a distinct apiculus and often a germ pore, firm and often thin walled, with pure and intense colours. Examination of many reference slides of basidiospores, identified by specialists in this group of fungi, showed that many were sufficiently distinctive to be recognizable as species, and the whole form a readily recognizable group. Spores of Coprinus spp., Boletus spp., Hypholoma spp., etc., were often seen. Psilocybe foenisecii and Bolbitius vitellinus were recognized with reasonable certainty as species. The occasional spores of Coniophora spp., were placed in the Unclassified group until their identity was recognized. As would be expected, most appeared in August and September (see Gregory \& Hirst, 1952) and our data suggest that peak numbers occurred when warm spells came about 2 weeks after periods with substantial rain. Taxonomically the Ganoderma type should of course, be included with the coloured basidiospores.

\section{Alternaria type (Fig. 2, scale C)}

This group was widely interpreted to include dark muriform conidia differing from one another as much as the rounded spores of Stemphylium botryosum differ from the club-shaped conidia of Alternaria tenuis, which was by far the most common genus included. The group, more important as saprophytes than parasites in this country, was most common during August particularly in warm dry periods following wet spells, and Alternaria was the dominant genus.

\section{Ustilago type (Fig. 2, scale C)}

This category, unlike the last, was narrowly interpreted and included only spores morphologically indistinguishable from Ustilago avenae (including $U$. perennans). Spores of most other smuts would have been placed in the Unclassified type, either because of the difficulty of distinguishing them from Fungi Imperfecti such as Periconia spp., or because, like Tilletia and Urocystis, they were uncommon. Spores in the Ustilago category may well have come considerable distances, but there were local sources both on cereals and on Arrhenatherum elatius, a common weed grass. The seasonal periodicity of the group is clearly determined by its exposure on infected grass inflorescences in June and early July. Few occur later, even during harvesting.

\section{Erysiphe type (Fig. 2, scale C)}

This group comprised conidia (Oidium state) derived from powdery mildews. Erysiphe graminis probably predominated, but $E$. polygoni was also seen and the conidia of other genera may have made a small contribution. 
The group was present throughout the season, although in the latter part they were too few for accurate representation on the scale used. Cereal crops were probably the most important source, and Last $(1954,1955 b)$ showed that late-sowing rendered crops susceptible. A late-sown crop of spring barley to the south-west of the trap was heavily attacked in June, and this important local source doubtless dominated others in determining the seasonal periodicity found for this group.

\section{Unclassified types (Fig. 2 scale C)}

The composition of this group changed considerably throughout the season; spores were included in it for the following reasons:

(1) Spores that could have been referred to 'generic types', but which were often too rare to form quantitatively significant components of the airspora. These included spores of the genera Tilletia, Urocystis, Epicoccum, Tetracladium, Lycoperdon, Fusarium (very rare), Sordaria, Chaetomium, Peronospora, Torula, Penicillium and Aspergillus. Some of these have been found abundantly when sampling special environments, e.g. Penicillium and Chaetomium in a mushroom house.

(2) Spores which could be less precisely recognized, such as the conidia of the Entomophthoraceae, spore types of the rusts other than the uredospores, the soredia of lichens, spores of bryophytes and pteridophytes other than Pteridium.

(3) Spores not classifiable because of unsuitable orientation on the adhesive surface or because they were partially obscured by debris or other particles.

(4) Spores, perhaps distinctive, but unclassifiable because of ignorance on the part of the recorders.

The Unclassified category is needed to fulfil the object of the survey, which was to make a total count of spores, and not only to group the forms occurring most abundantly into named taxonomic categories. Such a heterogenous group could hardly be expected to show any clear relationships between numbers and the weather. The fact that the group was most common during wet weather in August merely emphasizes how little is known of the many featureless components of the damp air-spora.

\section{'Hyaline rods' type (Fig. 2, scale $C$ )}

This was an abundant and distinctive group to the identity of which we have few clues. The spores were about 3-5 $\times 0 \cdot 7-1 \cdot 0 \mu$. with somewhat rounded ends, straight or slightly curved and the wall refractile like that of a fungus spore. Sometimes a minute granule inside the cell appeared to touch the end wall. Many spores were distinctly biguttulate and resemble spores of Phoma or Phyllosticta type, but they were smaller than most species known in Britain. They might be the microconidia ('spermatia') of a pyrenomycete such as one of the Mycosphaerellaceae. They were small for ascospores and seldom occurred in groups on the trace. The seasonal periodicity of the group resembles that of other members of the damp air-spora already described, e.g. Helicospores, Tilletiopsis, and ascospores $\mathbf{A}$ and $\mathbf{B}$. 


\section{Cladosporium type (Fig. 2, scale D)}

Reference slides showed that the spores from a single specimen or culture of $C$. herbarum varied greatly in size, colour and roughness of the surface. Nevertheless, the scanner soon learns to identify members of this category with confidence, especially after encountering the digitate clusters of conidia often found on the slides on windy days, which contain all stages of development. C. herbarum formed the majority of the catch but C. macrospora (Richards, 1953) was recognizable and other species were no doubt included. This group was a dominant constituent of the daytime air-spora, particularly in rural districts. It was present in considerable numbers from June to October, with maximum concentrations in August. The number in the air changes very rapidly with changing weather (Hirst, 1953; Gregory, 1954); spores are produced abundantly in high temperatures and high humidity. The seasonal maximum probably depends on the accumulation of dead plant tissues among grasses, cereal and root crops, during the late summer when conditions favour spore production.

\section{Hyaline basidiospores (Fig. 2, scale D)}

It would have been desirable to subdivide this category, but this was not realized when scanning was started. One subgroup would contain the hyaline basidiospores of the Agaricales, whose spores show a periodicity similar to those in the coloured basidiospore group. The second subgroup, vastly more abundant and typically predominant late at night and in the early morning, and by day during damp weather, has much smaller spores and is now recognized as belonging to the genus Sporobolomyces. This connexion has been confirmed by direct examination of the sporing colonies on cereal leaves by Last $(1955 a)$ and by drawing air through filter-paper, which was later incubated on nutrient medium to develop the pink colonies of Sporobolomyces.

The highest concentrations of this group occur in the early hours of mornings of low turbulence accompanied by long periods of warm humid nights. The category is second only to Cladosporium in average concentration over the whole season and actually achieved the highest daily mean concentration (Table 1).

\section{RESULTS TWENTY-FOUR METRES ABOVE GROUND}

Information about changes in spore concentration at different heights above ground would help to answer many questions concerning the distances to which spores are transported and the rate at which they are deposited. Grainger (1954) and Last (1955c) reported steep gradients of spore concentration in and just above crops. Others, mostly in North America, have caught spores from aircraft flying at considerable altitudes. Several long series of trap - exposures have been made on the roofs of buildings, chiefly by people studying allergy, but there are few records of simultaneous spore trapping at different heights. Part of the present series compares spore concentration $2 \mathrm{~m}$. above ground and at a well-exposed site high in the zone of frictional turbulence, 
$24 \mathrm{~m}$. above ground. The data quoted are limited to the twelve commonest groups on 24 of the days between 20 June and 14 July. The traps were separated by a horizontal distance of $100 \mathrm{yd}$. and differed in their exposure to certain local spore sources, notably a spring-sown barley crop to the south-west which was heavily attacked by Erysiphe graminis. The average spore concentration of the twelve groups selected measured at $24 \mathrm{~m}$. was $81.5 \%$ of that measured at $2 \mathrm{~m}$. The percentage distribution among the groups varied considerably for individual groups as shown in Table 2, which also shows the number of days when trap $B$ caught the same number or more spores than trap $A$. The spore

Table 2. Comparison of catches from trap $A$ (2 m. above ground level) and trap $B$ (24 m. above ground level); 20 June-14 July (24 days) 1952

$\quad$ Category
Grass pollens
Other pollens
Cladosporium
Ustilago
Coloured basidiospores
Hyaline basidiospores
Alternaria
Erysiphe
Botrytis
Tilletiopsis
Hyaline rods
Unclassifled

\begin{tabular}{|c|c|}
\hline ' $B$ ' as $\%$ of ' $A$ ' & $\begin{array}{l}\text { No. of days out of } 24 \\
\text { when ' } B \text { ' equalled } \\
\text { or was greater than } \\
\text { ' } A \text { ' }\end{array}$ \\
\hline 71 & 11 \\
\hline 68 & 12 \\
\hline 90 & 7 \\
\hline 86 & 9 \\
\hline 204 & 13 \\
\hline 66 & 11 \\
\hline 114 & 16 \\
\hline 37 & 2 \\
\hline 91 & 14 \\
\hline 92 & 14 \\
\hline 110 & 16 \\
\hline 97 & 11 \\
\hline
\end{tabular}

No. of days out of 24 when ' $B$ ' equalled or was greater than

concentration at the higher trap was unexpectedly large, particularly so with spore types characteristic of the night air-spora usually most common when turbulence and convection are slight. Twice as many coloured basidiospores were caught by the higher trap. This difference is, however, largely accounted for by 2 days when the concentration at trap $B$ was 8 and 10 times that at trap $A$; these were the 2 days when the spore concentrations were largest. A detailed analysis of the comparison is unlikely to be profitable, for previous work close to the ground has shown the necessity for hourly counts and weather records if the factors governing spore concentration are to be understood.

\section{DISCUSSION}

No reference has been made in these results to one important group of airborne micro-organisms, the bacteria. Individual bacteria are particles smaller than the trap was designed to catch. They were seldom noticed while scanning unstained preparations (staining prevents the use of natural spore colour, a valuable aid to the recognition of many fungus spores). In outdoor air, bacteria are usually dispersed on 'rafts' composed of soil particles or vegetable debris, which prevent their being seen during scanning. Special methods exist for sampling air-borne bacteria (Bourdillon, Lidwell \& Lovelock, 1948). 
Where these have been used out of doors in summer, they suggest that fungus spores are present in greater number than bacteria. It is interesting to note that the average total microbial count of 50 units $/ \mathrm{m}^{3}$ recorded by Bourdillon et al. (1948) is strikingly low compared with our results. This may have been due to a low efficiency with which the larger particles were collected by the apparatus then used; probably 25 units $/ \mathrm{m}^{3}$ represents a typical concentration of the bacteria capable of growing on blood agar. This is near the detectable threshold concentration by the methods used in the survey (i.e. the number which must be present before one microbe should appear in the area scanned). Hence, few bacteria should have been seen except at peak times.

Mycologists and students of allergy will note with surprise that Penicillium and Aspergillus spp. have not been given separate categories. Although readily recognizable when in chains, the individual conidia from these fungi have few characteristic features and were therefore placed in the 'Unclassified' category. We have no doubt that the method used here tends to underestimate these genera. The available evidence, however, shows that Penicillium spp. form only a very small proportion of the spores in outdoor country air (Richards, $1954 a$; 1956). High numbers, which occur chiefly in winter, are associated with the air of special environments; indoors, particularly associated with food and in glasshouses and in cities (Richards, 1954b; Maunsell, 1954).

The most significant additions to the air-spora indicated by this survey are the important autumnal contribution from basidiomycetes and the enormous abundance of Sporobolomyces. Numerically Sporobolomyces rivals Cladosporium, and the related category Tilletiopsis is by no means negligible. Both Sporobolomyces and Tilletiopsis were unknown until 1930. Though predominating by night, Sporobolomyces may persist in great numbers when the humidity remains high during the following day.

Most ascospores were placed in the 'Unclassified group'. This may disguise their importance, particularly in wet weather. Studies of Venturia inaequalis, the fungus which causes apple scab, have shown that in orchards in early spring this one species may be an important, and at times the dominant, constituent of the air-spora (Hirst, Storey, Ward \& Wilcox 1955). Similarly, little prominence was given to splash-dispersed spores. These are common among both saprophytic and parasitic fungi, but as they are often relatively featureless they are difficult to classify visually. It is possible that spores suspended in large splash droplets may not reach or be able to traverse the slit orifice of the trap unless the diameter of the droplet has been so decreased by evaporation that it has a terminal velocity similar to that of the larger spores. Workers using culture methods have recorded a small proportion of Phoma colonies (Richards, 1956). However, colonies developing on culture media may have arisen from an ascospore or from a splash-dispersed conidium, although in culture they may produce only one type of spore, or neither. Richards's Phoma component may therefore be represented either as part of our 'Hyaline rods' group or as ascospores included in the 'Unclassified group'.

The seasonal periodicities differ greatly in character, no doubt because of complex interaction of physical and biological factors. Some groups are 
present almost continuously throughout the period studied, with only slight changes in concentration, for example Botrytis, the helicospores and the hyaline rods. Others display pronounced peaks, such as those of pollens Erysiphe, Ustilago and Phytophthora. Non-selective sampling suggests some surprising differences in the spore productivity of various species. None of the sporophores of Ganoderma contributing to the catches were close to the trap and their total surface area must have been minute compared with that occupied by sporing lesions of Phytophthora infestans on the quarter acre of potatoes at the centre of which the trap was placed. Yet Ganoderma provided both higher maximum and total catches than Phytophthora over a longer period and in a greater variety of weather. Almost the only characteristic shared by all the spores studied is that of being visible under the compound microscope. A method which will collect continuously all spores with little partiality for shape or size, and which is relatively little influenced by changes in external conditions, may well be claimed useful for making general surveys of atmospheric spore content. No existing method is, however, perfect. The present one has the advantage of completeness and representative sampling, but it cannot distinguish live spores from dead ones, and only a limited number of spores is certainly identifiable. The importance of these factors depends much on the purpose for which the information is collected.

The constitution of the air-spora is studied chiefly because of its importance in studying respiratory allergy or diseases of plants. For studies of allergy the count of total numbers of spores which we have made may be very satisfactory, because it includes pollens, obligate parasites, dead spores and others which will not grow or sporulate in culture. It also allows fairly easy calculation of the total mass of spores inhaled by patients. The suction rate of $10 \mathrm{l} . /$ min. approximates to the volume inhaled by an adult engaged in gentle activity. The results show that a very few types are of predominant importance numerically; fortunately this allows a large proportion to be classified 'generically', with reasonable accuracy. The method fails to give adequate records of a few important known allergens, for reasons which have already been discussed.

Plant pathologists need to know the large changes which occur in the whole air-spora, but they will naturally be interested more in the behaviour of individual organisms or groups of closely related species. Many important plant-pathogenic fungi have spores which are quite characteristic; many others cannot be recognized visually with any certainty. Further study will require the development of specialized techniques for identifying and estimating the number of effective reproductive units deposited on sites where they can cause disease.

These observations were made in an area devoted to mixed farming, with land-use typical of large areas of the Midlands and the south and east of England. Local sources are known to have affected the catches to some extent; for instance, the effects of individual crops are discernible. Almost all the spores, except from Agaricaceae, were of types found on vegetable matter dead or alive. There is no evidence, at Rothamsted, to support the claims by Pady 
\& Kapica (1953) that soil micro-organisms contribute a significant proportion of the air-spora. The composition of the air-spora would no doubt have been different had the traps been situated on a moor or in woodland. The major changes of spore concentration seem to depend on the weather and phenology of the local vegetation and its associated fungal flora.

\section{REFERENCES}

Bernstein, T. B. \& Feinberg, S. M. (1942). Air-borne fungus spores. A five-year survey of daily mold spore content of Chicago air. J. Allergy, 13, 231.

Bourdillon, R. B., LiDwell, O. M. \& Lovelock, J. E. (1948). Studies in air hygiene. Spec. Rep. Ser. med Res. Coun., Lond. no. 262, p. 356.

Grainger, J. (1954). Spore production by Helminthosporium avenae. Trans. Brit. mycol. Soc. 37, 412.

Gregory, P. H. (1950). Deposition of air-borne particles on trap surfaces. Nature, Lond. 166, 487.

Gregory, P. H. (1954). The construction and use of a portable volumetric spore trap. Trans. Brit mycol. Soc. 37, 390.

Gregory, P. H. \& Hirst, J. M. (1952). Possible role of basidiospores as air-borne allergens. Nature, Lond. 170, 414.

HrRst, J. M. (1952). An automatic volumetric spore trap. Ann. appl. Biol. $39,257$.

Hrrst, J. M. (1953). Changes in atmospheric spore content: diurnal periodicity and the effects of weather. Trans. Brit. mycol. Soc. 36, 375.

Hirst, J. M., Storey, I. F., Ward, W. C. \& Wilcox, H. J. (1955). The origin of apple scab epidemics in the Wisbech area in 1953 and 1954. Plant Path. 4, 91 .

HydE, H. A. (1952). Studies in atmospheric pollen. V. A daily census of pollen at Cardiff for the six years 1943-8. New Phytol. 51, 281.

Hyde, H. A. \& Williams, D. A. (1945). Studies in atmospheric pollen. II. Diurnal variation in the incidence of grass pollen. Nere Phytol. 44, 83.

Hyde, H. A. \& Williams, D. A. (1946). Studies in atmospheric pollen. III. Pollen production and pollen incidence in Ribwort Plantation (Plantago lanceolata L.). New Phytol. 45, 271.

Ingold, C. T. (1939). Spore Discharge in Land Plants. Oxford University Press.

LAST, F. T. (1954). The effect of time of application of nitrogenous fertilizer on powdery mildew of winter wheat. Ann. appl. Biol. 41, 381.

LAST, F. T. $(1955 a)$. Seasonal incidence of Sporobolomyces on cereal leaves. Trans. Brit. mycol. Soc. 38, 221.

LAST, F. T. (1955b). Effect of powdery mildew on the yield of spring-sown barley. Plant. Path. 4, 22.

LAST, F. T. $(1955 \mathrm{c})$. The spore content of air within and above mildew-infected cereal crops. Trans. Brit. mycol. Soc. 38, 453.

MAUNSELL, K. (1954). Concentrations of air-borne spores in dwellings under normal conditions and under repair. Int. Arch. Allergy, N.Y. 5, 373.

Miquel, P. (1877-1899). Annu. Obs. Montsouris.

Neill, J. C. \& Armstrong, C. S. (1955). An aerial survey of ascospore distribution of blind-seed disease of ryegrass (Gloetinia (Phialea) temulenta). N.Z. .J. Sci. Tech. 37, 106.

PADY, S. M. \& KAPICA, L. (1953). Air-borne fungi in the arctic and other parts of Canada. Canad. J. Bot. 31, 309.

Richards, M. (1953). Saprophytic Cladosporium in Britain. Nature, Lond. 171, 615. 
RichARDS, M. (1954a). Seasonal periodicity in atmospheric mould spore concentrations. Acta allerg., Kbh. 7, 357.

Richards, M. (1954b). Atmospheric mould spores in and out of doors. J. Allergy. 25, 429.

Richards, M. (1956). A census of mould spores in the air over Britain in 1952. Trans. Brit. mycol. Soc. 39, 431.

Schoenauer, M. (1876). Annu. Obs. Montsouris.

Walton, C. H. A. \& Dudley, M. G. (1940). Pollen survey in Manitoba. Canad. med. Ass. J. 42, 430.

(Received 19 February 1957) 